\title{
Concepções de Inclusão Digital na Formação Inicial de Educadores
}

\author{
Karina Marcon ${ }^{1}$, Marie Jane Soares Carvalho ${ }^{2}$ \\ ${ }^{1}$ Professora do Centro de Educação a Distância da Universidade do Estado de Santa \\ Catarina (CEAD/UDESC); Doutora em Educação (Bolsista CNPq) pela Universidade \\ Federal do Rio Grande do Sul (UFRGS). \\ ${ }^{2}$ Professora Associada do Programa de Pós-Graduação em Informática na Educação da \\ Universidade Federal do Rio Grande do Sul (UFRGS) \\ karina.marconeudesc.br, marie.janedufrgs.br
}

\begin{abstract}
This article socialize the results of a doctoral research, whose aim was to analyse the understanding and practice of digital inclusion in the early training of e-educators on distance learning at the Open Universities of Brazil and Portugal. Theses and dissertations were studied for the development of a state of the art for the concept of digital inclusion in and field research was carried out in the courses of Degree in Education (Portuguese Open University) and Distance Pedagogy (Santa Catarina State University/UAB). By means of a multicase study, one of search categories aimed to understand the teachers' conception of digital inclusion, analysis presented in this text.

Resumo. Esse artigo socializa os resultados de uma pesquisa doutoral, cujo objetivo foi analisar a compreensão e a prática da inclusão digital na formação inicial de educadores na modalidade a distância das Universidades Abertas do Brasil e de Portugal. Foram realizadas pesquisas em teses e dissertações para a criação de um estado da arte sobre o conceito de inclusão digital e uma pesquisa de campo nos cursos de Licenciatura em Educação (Universidade Aberta de Portugal) e Pedagogia a Distância (Universidade do Estado de Santa Catarina). Por meio de um estudo multicaso, uma das categorias da pesquisa teve o objetivo de compreender a concepção de inclusão digital pela equipe docente, análise apresentada nesse texto.
\end{abstract}

\section{Introdução}

Para a discussão sobre o conceito de inclusão digital partimos de estudos prévios realizados na área e fizemos um levantamento bibliográfico para apresentar novas perspectivas sobre esse conceito. Por se tratar de um estudo multicaso, abrangente das realidades brasileira e portuguesa, julgamos essencial desvelar como se concebe o conceito de inclusão digital em ambos os países. Definimos os anos de 2011, 2012, 2013 e 2014 como nosso horizonte temporal. Para realizar o estado da arte brasileiro elegemos a Biblioteca Brasileira de Teses e Dissertações (BDTD) como nosso banco de dados, e encontramos um total de 12 teses de doutorado e dez dissertações de mestrado. Para concretizar o levantamento teórico de Portugal, utilizamos o Repositório Científico de Acesso Aberto de Portugal (RCAAP), sendo que o estudo se concretizou com um total de duas teses de doutorado e 12 dissertações de mestrado. 
Ao refletir sobre as contribuições trazidas por todos os pesquisadores que visitamos no estado da arte brasileiro e também em estudos anteriores, elencamos a seguir algumas características que julgamos serem fundamentais e, por isso, merecem ser consideradas ao pensarmos o conceito de inclusão digital:

- democratizar o acesso às tecnologias digitais e garantir a equidade (MEDEIROS, 2013; DUSYK, 2013; CASARIN, 2014);

- permitir, na apropriação tecnológica, que as pessoas atuem como provedores ativos dos conteúdos que circulam na rede (TAKAHASHI, 2000; BONILLA, 2004; TEIXEIRA, 2010a; ODANAI, 2013);

- vivenciar uma cultura de redes (PRETTO, 2006; TEIXEIRA, 2010a);

- promover a utilização das tecnologias a favor dos interesses e necessidades individuais e comunitários, com responsabilidade e senso de cidadania (TAKAHASHI, 2000; TEIXEIRA, 2010a; RODRIGUEZ, 2011; RIBEIRO, 2012; SANTOS, 2012);

- valorizar a diversidade (TEIXEIRA, 2010a; PEDROSA, 2011);

- desenvolver habilidades e capacidades para a era digital (ODAINAI, 2013);

- romper o ciclo de consumo e dependência tecnocultural (TEIXEIRA, 2010a);

- buscar a fluência digital, com processos que aprimorem a ação e a autonomia dos sujeitos e o exercício da liberdade e da cidadania na rede (TEIXEIRA, 2010a; PEDROSA, 2011; ALENCAR, 2013; BOTELHO-FRANCISCO, 2014);

- compreender inclusão digital como um conceito multidimensional, que envolve dimensões digital, informacional e social (PEREIRA, 2014; ARAÚJO, 2013).

Ao findar o mapeamento teórico sobre inclusão digital em Portugal, destacamos principalmente a compreensão desses trabalhos pelo conceito de literacia digital, que expressa a necessidade de que se faça um uso eficiente das Tecnologias Digitais de Tede (TDR) contemporâneas, além de reconhecer a transformação gerada pela cultura digital, o potencial das tecnologias para a vida humana e para a educação, a necessidade de usabilidade técnica e o desenvolvimento de competências, bem como a urgência de assumir-se como um ser produtor de conhecimento, de conteúdos e de cultura.

Assim, considerando a diversidade de perspectivas teóricas e da complexidade entorno da temática, propomos um conceito de inclusão digital que subsidia nossas análises e inferências na pesquisa. Compreendemos inclusão digital como um processo que fomenta apropriações tecnológicas nas quais os sujeitos são compreendidos como produtores ativos de conhecimento e de cultura, em uma dinâmica reticular que privilegia a vivência de características nucleares na sociedade contemporânea, como a interação, a autoria e a colaboração. Inclusão digital pressupõe o empoderamento das tecnologias, a garantia à equidade social e à valorização da diversidade, suprindo necessidades individuais e coletivas, visando à transformação das próprias condições de existência e o exercício da cidadania na rede. Nessa perspectiva, entendemos que o conceito de inclusão digital perpassa por três eixos: 1) Apropriação/Fluência/Empoderamento Tecnológico; 2) Produção/Autoria individual/coletiva de conhecimento e de cultura e 3) Exercício da cidadania na rede.

O eixo 1 - Apropriação/Fluência/Empoderamento Tecnológico - diz respeito ao acesso, à apropriação, ao domínio e à fluência tecnológica, elementos necessários para 
reconhecer e transitar pela linguagem hipermidiática, condutora da cultura digital. É nesse eixo que dialogamos com os diferentes níveis de apropriação tecnológica e letramento digital, reconhecendo a necessidade de se assegurar a equidade de acesso, bem como oportunizar o empoderamento dos sujeitos por meio das tecnologias digitais de rede, reconhecendo seu potencial comunicacional, educativo e político.

O eixo 2 - Produção/Autoria individual/coletiva de conhecimento e cultura compreende os sujeitos como autores e produtores ativos de conhecimento e de cultura. As TDR potencializam a vivência de processos comunicacionais interativos, autorais e colaborativos. Com a abertura dos polos de emissão, a cibercultura autoriza o sujeito a se expressar, interagir e participar. Supera-se a comunicação unidirecional e os limites temporais e espaciais, privilegia-se a interação todos-todos. É nesse eixo que correlacionamos a inclusão digital com a apropriação crítica e criativa das tecnologias digitais de rede, na qual os sujeitos, além de consumidores, são autorizados a criar, produzir e compartilhar informações, conhecimentos e cultura.

O eixo 3 - Exercício da cidadania na rede - refere-se à garantia de participação política dos sujeitos no ciberespaço e à valorização da diversidade social. Reconhecemos que a apropriação tecnológica pode acontecer de acordo com a realidade e interesses de cada sujeito, isso é, cada um apropria-se das tecnologias de acordo com as suas necessidades individuais, coletivas ou comunitárias. Nesse eixo, fazemos uma interlocução com propostas que objetivam o reconhecimento das TDR como propulsoras de transformação das próprias condições de existência e do exercício da cidadania na rede.

No item a seguir apresentamos qual a concepção dos docentes sobre esse conceito, reflexão que se faz fundamental para compreendermos de que forma os professores vêm conduzindo suas práticas pedagógicas. Importante destacar que tais dados foram obtidos em entrevista pessoal estruturada com os esses profissionais, que atuam nas disciplinas que possuem interface com as tecnologias educacionais dos cursos de Pedagogia do Cead/Udesc e de Licenciatura em Educação da UAb Portugal. Ao todo foram entrevistados quatro professores no Cead/Udesc e quatro na UAb Portugal. Ao reconhecer a concepção dos professores, estamos buscando compreender as diretrizes que orientam seus trabalhos.

\section{Concepções de inclusão digital pela equipe docente do Centro de Educação a Distância da Universidade do Estado de Santa Catarina}

Para dar início à nossa reflexão sobre as concepções de inclusão digital na perspectiva dos docentes do Cead/Udesc, trazemos a opinião de um professor que faz repercutir uma questão sobre as várias terminologias que são utilizadas para referir-se aos processos de apropriação tecnológica:

[...] Inclusão Digital, [...] eu acho que é ter acesso ao computador. Agora existe uma outra coisa que é a alfabetização digital, porque você pode ter um computador e não usar todas as potencialidades dele, mas você tá incluído digitalmente, você concorda? Você ainda usa o e-mail, usa as redes sociais [...]. Isso é inclusão digital, é o acesso ao computador. E [...] a gente sabe que é uma questão de mercado, entendeu, o mercado inclui as pessoas digitalmente, agora o mercado não alfabetiza as pessoas digitalmente. Então elas entram dentro deste universo e elas não sabem o que fazer ali dentro. [...] Então eu acho que uma coisa é inclusão digital e outra coisa é alfabetização digital. [...] Pra mim há uma diferença muito grande entre inclusão e alfabetização. Estão ligadas, mas são diferentes (PE-Cead02). 
Conforme defendemos em nossa proposta conceitual, entendemos que o conceito de inclusão digital extrapola o acesso às tecnologias, perpassando por outros dois eixos que dizem respeito à apropriação crítica, autoral e colaborativa dos recursos tecnológicos, bem como o exercício de cidadania na rede, acenando sobretudo para a garantia de participação política dos sujeitos no ciberespaço e para a valorização da diversidade social. Com relação à concepção de alfabetização digital trazida pelo educador, tal terminologia também foi trazida pelo Livro Verde (TAKAHASHI, 2000), porém, em nossa análise, em contexto semântico que se coaduna com o que entendemos ser inclusão digital, principalmente no que se refere à "utilização dessas mídias em favor dos interesses e necessidades individuais e comunitários, com responsabilidade e senso de cidadania" (TAKAHASHI, 2000, p. 31). Alguns autores que fazem parte do nosso estudo sobre o conceito de inclusão digital questionam o termo "alfabetização digital", por entenderem se tratar de uma visão reducionista de acesso às tecnologias. Porém, é possível compreender nas palavras do docente PE-Cead02, que sua compreensão de alfabetização digital está relacionada com o que entendemos ser inclusão digital, por mais que sua visão seja expressada de forma diferente da nossa.

Outro docente também faz analogia à alfabetização e ao letramento:

[...] É tentar garantir o acesso às tecnologias de informação e comunicação. [...] Fazendo uma analogia com relação a alfabetização e letramento. Não que você tem que alfabetizar o aluno para a inclusão digital, mas uma proposta de letramento, que ele consiga dar, utilizar essas ferramentas, que contribua para sua vida social, econômica, pessoal, enfim, que ele consiga utilizar isso. Então, [...] eu vejo como inclusão digital, de tentar garantir então o acesso a essas tecnologias, mas que ele faça uso disso, tenha um sentido e um significado para o seu dia a dia, pro seu entorno (PE-Cead01).

É significativo o fato de que o docente estabelece a similaridade com o conceito de letramento, porém não institui diferenças entre letramento e inclusão digital, apenas apontando as convergências entre as duas concepções. O conceito de letramento também é trazido por Jenkins (2009) e questionado por Teixeira (2010b), quando aponta que os dois conceitos não alcançam as possibilidades das tecnologias digitais de rede, e, por isso, propõe o compromisso em buscarmos fluência digital.

Os docentes PE-Cead04 e PE-Cead03 também têm suas concepções de inclusão digital associadas ao eixo 3 do nosso conceito norteador:

Acho que inclusão digital não é apenas estar inserido no meio de uma sociedade digital, mas é você conseguir fazer uso desses meios digitais na sua vida pessoal, profissional, e que você tenha conhecimento do que seriam essas ferramentas. [...] Acho que a inclusão vai mais do que só estar inserido em um contexto digital (PE-Cead04).

[...] Entendo que não é só ter acesso aos recursos digitais, é você ter possibilidade de se apropriar, e refletir sobre as possibilidades, o potencial. Enfim, não é só ter acesso, mas é você conseguir se apropriar, conseguir utilizar, ter condições de utilizar e fazer um uso crítico e reflexivo dessas tecnologias, procurando saber de que forma elas podem modificar a sua vida, melhorar a sua vida ou piorar a sua vida. Então eu acho que a inclusão ela passa também por uma reflexão das implicações positivas e negativas das tecnologias na nossa vida (PE-Cead03).

Vimos em outros autores que discutem o conceito de inclusão digital, que existe uma preocupação em promover a utilização das tecnologias a favor dos interesses e das necessidades individuais e comunitárias, com responsabilidade e senso de cidadania (TAKAHASHI, 2000; TEIXEIRA, 2010a; RODRIGUEZ，2011; RIBEIRO， 2012; SANTOS, 2012). Atualmente, há uma inquietação cada vez maior para o 
desenvolvimento de tecnologias, aplicativos e recursos que qualifiquem a vida cotidiana dos sujeitos com mais conforto.

Uma outra perspectiva trazida pelo docente PE-Cead02 é com relação à inclusão digital e aos processos educativos, principalmente no que diz respeito à apropriação de tecnologias por professores para que ressignifiquem suas práticas pedagógicas.

E aí o educador, ele tem um pouco essa... principalmente o educador que vai educar educadores, o formador de formadores... Esse cara ele tem dever, vou usar a palavra dever mesmo, de desmistificar essas ferramentas para que o cara tenha uma visão crítica em relação a elas, saber que inclusive tem pessoas que não tem acesso ao computador, para poder trabalhar as TICs de uma forma que realmente potencialize a aprendizagem [...] Por exemplo, a matemática ela pode se tornar mais dinâmica dentro do computador, e aquelas continhas que você tem que ficar lá escrevendo em um caderno, ou que você poderia escrever no word do mesmo jeito, você pode ter por exemplo jogos, outros caminhos para você trabalhar a matemática sem que o aluno perceba inclusive que ele está estudando a matemática (PE-Cead02).

O posicionamento desse professor é relevante para nossos estudos, porque fala da necessidade, na formação inicial de educadores, de desmistificar as tecnologias, possibilitar uma apropriação crítica dessas e, sobretudo, viabilizar formas para oportunizar o reconhecimento do potencial pedagógico e educativo de muitos recursos que são abertos e que estão disponíveis para serem aplicados em contextos educativos. São recursos que deixam de ser utilizados por muitas vezes serem desconhecidos de professores que atuam em sala de aula.

Entendemos ser esse um dos grandes desafios na formação inicial de educadores no que tange a processos de inclusão digital, a saber: encontrar estratégias didáticas que apontem os caminhos alternativos para trabalhar conteúdos. Acreditamos que são percursos que não anulam as práticas pedagógicas anteriores, mas enriquecedores das práticas pedagógicas atuais, principalmente se considerarmos esse novo perfil de estudante que encontramos em sala de aula.

Sobre essa questão, entende o docente PE-Cead02 que "[...] a alfabetização digital num mundo como o nosso deveria vir desde a pré-escola, porque hoje uma criança de dois anos tem um tablet ou brinca com o celular do pai e da mãe, que tem todas as funcionalidades de um android [...]" (PE-Cead02). As crianças cada vez mais precocemente estão tendo contato com as tecnologias, principalmente as móveis, por meio de tablets e smartphones. São recursos intuitivos que permitem que, com um pouco de observação, esses jovens já consigam, de forma axiomática, operar seus aplicativos favoritos, abrindo-os e fechando-os quando bem entendem.

Essa convergência midiática, que opera sobretudo na forma de agir das pessoas (JENKINS, 2009), traz influências significativas para a sala de aula e para as práticas docentes. O professor PE-Cead01 ressalta justamente o desafio de ser docente nesse contexto tecnológico digital:

[...] E na sala de aula é o grande desafio, porque os alunos estão ali, estão com tablet, estão acessando tudo e como é que você vai incorporar isso nas suas aulas? Como é que vai dar essa convergência né, como é que vai dar essa convergência para as novas práticas? (PECead01).

São questionamentos interessantes, que nos fazem refletir inclusive sobre nossa própria atuação como formador de formadores. Estamos promovendo processos de inclusão digital em nossos cursos de graduação? Esses processos são capazes de 
questionar as práticas pedagógicas atuais e promover pedagogias mais adequadas a esse espaço e tempo em que se vive? Como essas práticas acontecem na modalidade a distância? Entendemos que o desenho didático e a atuação pedagógica em cursos na modalidade a distância precisam preconizar principalmente o que categorizamos como eixo 2 em nosso conceito de inclusão digital, ou seja, a produção/autoria individual/coletiva de conhecimento e de cultura. Pensamos que isso acontece por meio da apropriação de plataformas colaborativas e, sobretudo, do exercício dessas competências em nossas metodologias docentes.

No item a seguir, apresentamos as concepções de inclusão digital pelos professores da Universidade Aberta de Portugal.

\section{Concepções de inclusão digital pelos professores da Universidade Aberta de Portugal}

O que eu entendo por inclusão digital é, sobretudo, a integração de todos nesta sociedade digital e tudo o que isso implica. [...] É, de certa forma, criar uma sociedade em que todos os indivíduos, de forma e de fato democrática, consigam ter acesso às tecnologias e que compreendam o papel destas tecnologias nesta sociedade atual e, portanto, que não se exclua ninguém desta mesma sociedade em rede por não ter competências na área das tecnologias (PE-UAb01).

A fala do professor destacada acima aponta, inicialmente, para um nível de acesso, o que diz respeito fundamentalmente à percepção de que a inclusão digital precisa promover processos de apropriação, fluência e empoderamento tecnológico, tal como identificamos em nosso eixo 1. Mais do que integrar esses sujeitos na sociedade digital e oportunizar o acesso às tecnologias, esse docente crê que é nuclear compreender o papel dessas tecnologias, buscando a equidade social por meio do desenvolvimento de competências digitais. Essa mesma percepção de incluir para equalizar foi encontrada em trabalhos que compõem nosso estado da arte (MEDEIROS, 2013; DUSYK, 2013; CASARIN, 2014), e é um viés que enfatiza as lacunas existentes em uma sociedade ainda desigual de oportunidades quanto à apropriação tecnológica.

Nessa mesma perspectiva, entende outro docente que "inclusão digital, enfim, é toda uma dinâmica de ações e de intervenções que ajudam o indivíduo a saber lidar e a interpretar e manusear todas as ferramentas da ordem digital [...]" (PE-UAb04). Essa é uma compreensão que também têm relação com o eixo 1, porém com um viés mais técnico, mas que, igualmente, direciona a inclusão digital para o reconhecimento de uma nova dinâmica que precisa ser conhecida, manuseada e interpretada.

O professor PE-UAb02, no mesmo sentido, entende que

A literacia digital será a competência que cada um tem em aplicações digitais ou em contextos digitais. [...]. Uma literacia que poderá estar desenvolvida ou ter vários estágios de desenvolvimento. A inclusão digital é uma das, digamos, metas também do próprio curso e do próprio Modelo Pedagógico da Universidade, para fazer com que os estudantes se sintam, digamos, info ou digitalmente incluídos, ou seja, que desenvolvam as tais competências tecnológicas e digitais que lhe permitam melhorar a sua literacia digital (PE$\mathrm{UAb02)}$.

Percebemos nas entrevistas o quanto o Modelo Pedagógico da Universidade Aberta está presente nos discursos dos docentes, que reconhecem que um dos pilares dos cursos da UAb é a inclusão digital. A fala deste docente citado sobrevém, incialmente, do desenvolvimento de competências digitais, e aponta que a inclusão 
digital pode ter diferentes níveis. De natureza igual a essa visão, outros dois professores também compreendem que existem níveis de inclusão/literacia digital:

[...] Independentemente do nível, estamos a falar duma literacia mais básica ou de uma literacia mais avançada [...]. Aquilo que eu entendo é que nós não precisamos todos ser grandes especialistas na área da tecnologia [...]. Não é necessário nós dominarmos todas as ferramentas, mas parece-me que é importante nós conhecermos estas mesmas ferramentas e, portanto, depois aprofundar o conhecimento daquelas ferramentas que nós achamos que são importantes para aquilo que nós fazemos diariamente (PE-UAb01).

[...] temos outros níveis da inclusão digital que é saber lidar com a informação e o conhecimento digital, o que que se faz com aquilo, não é? E novas profissões vão aparecer e estão já a surgir ligadas a essas áreas [...] (PE-UAb04).

Podemos perceber que, no entendimento do professor PE-UAb01, os sujeitos não precisam ser especialistas na área das tecnologias. Acreditamos, sobretudo na formação inicial de educadores, de forma que não precisamos formar sujeitos que dominem aspectos técnicos da informática, mas que, nomeadamente, tenham minimamente um conhecimento que lhes possibilite fluência e trânsito em dispositivos, interfaces, softwares e aplicativos tecnológicos, além de tornar, primordialmente factível reconhecer o potencial educativo desses recursos. A fala desse docente também faz referência ao que outros autores Takahashi (2000), Teixeira (2010a), Rodriguez (2011), Ribeiro (2012) e Santos (2012) já ressaltaram, sobre a utilização das tecnologias a favor dos interesses e necessidades individuais e comunitários.

Já na percepção do docente PE-UAb04, fica claro seu entendimento de que é preciso que se desenvolva habilidades e capacidades para a era digital, pressuposto já encontrado no trabalho de Odainai (2013). Na opinião do docente PE-UAb03, a inclusão digital já superou a discussão técnica:

Eu acho que a inclusão digital ela passou da fase técnica, já não é uma discussão técnica, aqui pelo menos. Não se discute tecnicamente, virou uma literacia espontânea, poderia assim chamar a inclusão digital técnica. Aprende com o amigo, com o filho, com o vizinho, com quem seja. Virou uma coisa super espontânea, literacia espontânea. (PE-UAb03).

A colocação desse docente reflete um movimento cada vez mais comum em nosso cotidiano, principalmente considerando a presença de tecnologias móveis, comumente intuitivas e acessíveis aos sujeitos. Nesse mesmo ponto de vista, outro docente ressalta que "[...] por um lado, atualmente, aprendemos a usar quase intuitivamente as ferramentas, mas depois não sabemos fazer o seu uso, seja do ponto de vista educativo, seja do ponto de vista profissional, que aí já é preciso uma outra formação" (PE-UAb04). Esse, em nossa opinião, é o maior desafio da formação de educadores, possibilitar estratégias didáticas de apropriação de tecnologias, para que posteriormente, em sua prática profissional, consigam estabelecer relações entre os objetivos de aprendizagem e os recursos disponíveis.

Para o docente PE-UAb03 existe uma diferença conceitual entre inclusão e literacia digital, na qual a literacia digital "[...] é mais aprofundada. Essa é para além de saber utilizar, pra além de compreender, mas é aperfeiçoar, é usar aquilo em prol da própria pessoa" (PE-UAb 03). Em sua percepção, a inclusão digital fica no plano da utilização e compreensão da tecnologia, enquanto que a literacia digital seria um processo mais aperfeiçoado. $\mathrm{O}$ excerto a seguir elucida suas colocações:

Eu acho que a literacia, a diferença, então, resumindo, a inclusão digital, hoje em dia, mesmo sem sendo técnica, pra mim ela está além da técnica, ela está já num processo de 
amadurecimento de uso da tecnologia para si, e a literacia, num processo mais profundo, que é realmente a compreensão disso não como uma ferramenta, mas [...] como um artefato cultural (PE-UAb03).

Entendemos que os conceitos de inclusão e literacia digital são complementares e convergentes, e a concepção de literacia digital encontrada no contexto português se aproxima do conceito de inclusão digital estudado no Brasil. Continua o docente:

[...] a literacia digital [...] eu acho que é ir mais a fundo, ao tema da literacia, do aprender a utilizar, e principalmente gerenciar a informação, que é o que as pessoas têm muita dificuldade, que é gerenciar a informação, usar para si, aprender com ela, informalmente. Fazer daquilo uma inter-relação consigo mesmo, você como autor, você como estudante, você como profissional, relacionando essa informação. Eu acho que é aí que vai a literacia hoje, num campo mais aprofundado, para além da alfabetização digital, para além do uso das tecnologias, para além da discussão do "aprender a buscar a informação" (PE-UAb03).

A fala desse professor remete à perspectiva de uma apropriação tecnológica que promova a capacidade de gerenciar a informação e fomentar inter-relações pessoais enquanto sujeitos autores e produtores, narrativas que vem ao encontro do eixo 2 do nosso conceito de inclusão digital, ou seja, a produção/autoria individual/coletiva de conhecimento e de cultura. A percepção de outro docente também segue essa ideia:

Eu vejo a inclusão digital não centrada só nas ferramentas mas no uso que os indivíduos depois fazem das mesmas, e da comunicação e de uma certa literacia, que não é só como uma questão da aprendizagem dos números ou da leitura, mas das mídias e das ferramentas digitais no seu conjunto e aquilo que constroem (PE-UAb04).

É possível identificar, nessa opinião, a ideia de superação da instrumentalização para o uso das ferramentas, sendo a inclusão digital um processo que promove uma apropriação tecnológica com um viés comunicacional, além das práticas sociais construídas no contexto midiático e tecnológico. Outra compreensão que relaciona-se com esse eixo é a percepção do educador PE-UAb03, quando reflete que

[...] o processo ensino-aprendizado também é uma coisa única, sua, que é institucionalizada, mas antes de ser institucionalizada é sua. E a literacia digital tá fazendo isso hoje, tá fazendo com que as pessoas enxerguem o processo ensino-aprendizado como algo que eu posso fazer, [...] sem ser institucionalizado (PE-UAb03).

Essa afirmação diz respeito sobretudo à subjetividade que existe nos processos de ensino-aprendizagem, considerando principalmente a diversidade entre os sujeitos. Ao fazer uso de uma tecnologia, tem-se contato com diversos aplicativos, fontes de informação, recursos e interfaces que podem contribuir para a sua aprendizagem, e isso cada vez mais tende a ser um processo independente de instituições, ou seja, que deixa de ser institucionalizado e pode ocorrer de forma autônoma.

Esse mesmo docente ainda entende que "[...] temos todos uma grande responsabilidade, em todos os cursos há um conjunto de competências que [...] todo cidadão atual tem que possuir [...]" (PE-UAb03). Esse registro abaliza o desdobramento que classificamos como eixo 3 do nosso conceito de inclusão digital, nomeadamente o exercício da cidadania na rede, tema já abordado Santos (2012), Teixeira (2010a), Pedrosa (2011), Alencar (2013) e Botelho-Francisco (2014), principalmente quando tratam da fluência e da emancipação digital com processos que aprimoram a ação e a autonomia dos sujeitos e o exercício da liberdade na rede.

Por fim, entendemos que esse cenário, apresentado pelos docentes, corrobora nossa percepção de que o desenho didático de um curso a distancia pode potencializar 
processos de inclusão digital aos educadores em formação, além de práticas pedagógicas orientadas a essa dinâmica comunicacional e tecnológica em que vivemos.

\section{Considerações Finais}

Percebemos que a equipe docente que trabalha na Udesc tem a compreensão de que além da garantia de acesso às tecnologias, é preciso promover a utilização desses recursos a favor dos interesses e necessidades individuais e comunitários. Com relação à formação inicial de professores, entendem que inclusão digital implica, sobretudo, na apropriação das tecnologias para ressignificação da prática pedagógica.

Já para os docentes da Universidade Aberta, entendem que é preciso promover o acesso às tecnologias de informação e comunicação, impulsionando a equidade social e o alargamento de competências digitais. $\mathrm{O}$ conceito perpassa também pelo desafio de estimular o desenvolvimento de estratégias didáticas para estabelecer relações entre tecnologias digitais de rede e os objetivos de aprendizagem nos espaços educativos diversos, além de uma apropriação tecnológica com um viés comunicacional, transformando sua realidade a partir do potencial desses recursos.

Em nossa percepção, todos os professores envolvidos na pesquisa compreendem que o conceito de inclusão digital supera o acesso às tecnologias e está relacionado com o empoderamento do sujeito para a transformação da sua realidade. Observamos, também, que as narrativas dos docentes entrevistados perpassam pelos três eixos do nosso conceito de inclusão digital: 1) Apropriação/Fluência/Empoderamento Tecnológico; 2) Produção/Autoria individual/coletiva de conhecimento e de cultura e 3) Exercício da cidadania na rede, e que existe uma tensão entre os termos utilizados por eles nas definições do conceito de inclusão digital: alfabetização, letramento, literacia.

De modo geral, os docentes que atuam nas disciplinas que possuem interface com tecnologias educacionais compreendem que o conceito de inclusão digital supera o acesso às tecnologias e está relacionado ao desenvolvimento de competências digitais e à apropriação de tecnologias para a transformação da sua realidade. Após a redação deste item, fica evidente também que os professores envolvidos na pesquisa compreendem a relevância do conceito de inclusão digital na formação dos educadores.

\section{Referências}

Alencar, M. G. S. P. (2013) A política brasileira de inclusão digital no capitalismo contemporâneo: o elo perdido do Programa Casa Brasil. Tese (Doutorado em Políticas Públicas). Disponível em: <http://www.tedebc.ufma.br//tde_busca/arquivo. php? codArquivo =832>. Acesso em: 02 out. 2014.

Araújo, B. (2007). Universidade Aberta do Brasil. In: ARAÚJO, Bohumila; FREITAS, Katia Siqueira de (Orgs). Educação a Distância no contexto brasileiro: experiências em formação inicial e formação continuada. Salvador: ISP/UFBA.

Bonilla, M. H. (2004). Educação e Inclusão Digital. Disponível: <http:// www.twiki.ufba.br/twiki/bin/view/GEC/MariaHelenaBonilla>. Acesso: 26 out. 2012.

Botelho-Francisco, R. E. (2014) Interatividade e literacias emergentes em contextos de inclusão digital: um estudo netnográfico no programa AcessaSP. Tese (Doutorado). Disponível em: <http://www.teses.usp.br/teses/disponiveis/27/27154/tde-20052014152952/pt-br.php>. Acesso em: 05 out. 2014. 
Casarin, M. M. (2014). O Programa Um Computador por Aluno (PROUCA) e a Inclusão de alunos com deficiência. Tese (Doutorado em Educação). Disponível em: <http://www.lume.ufrgs.br/handle/10183/98598>. Acesso em: 05 out. 2014.

Dusyk, C. L. (2013). Teclado Virtual Silábico-Alfabético: Tecnologia Assistiva para Pessoas com Deficiência Física. Dissertação (Mestrado em Educação). Disponível em: <http://www.lume.ufrgs.br/handle/10183/79640>. Acesso em: 30 set. 2014.

Jenkins, H. (2009). Cultura da Convergência. 2 ed. São Paulo: Aleph.

Medeiros, A. C. J. P. (2013). Análise das políticas de inclusão digital da rede pública municipal de ensino de Uberlândia no período 1999-2012. Dissertação (Mestrado em Educação). Disponível em: <http://www.bdtd.ufu.br//tde_busca/arquivo.php?cod Arquivo $=4967>$. Acesso em: 28 set. 2014.

Odainai, A. A. S. (2013) A cultura participativa na educação: superando a perspectiva instrumental no uso dos mecanismos de comunicação digital nos sistemas básico e médio de ensino. Dissertação (Mestrado). Disponível em: <http://www.sapientia. pucsp.br//tde_busca/arquivo.php?codArquivo=15923 > . Acesso em: 26 set. 2014.

Pedrosa, N. B. (2011). Comunidade de formação e prática pedagógica indígena: inclusão digital e identidade cultural. Tese (Doutorado em Educação). Disponível em: <http://www.sapientia.pucsp.br//tde_busca/arquivo.php?codArquivo=14270>. Acesso em: 12 set. 2012.

Pereira, L. (2012). Conceções de literacia digital nas políticas públicas: estudo a partir do Plano Tecnologico de Educação. Tese (Doutorado Ciências da Comunicação). Disponível em: <http://hdl.handle.net/1822/19825>. Acesso em: 12 set. 2012.

Pretto, N. L. (2006). Políticas públicas educacionais no mundo contemporâneo. Liinc em Revista, v. 2, p. 10-27. Disponível em: <https://blog.ufba.br/nlpretto/? page_id=388>. Acesso em: 26 out. 2012.

Ribeiro, R. (2012). O uso de tecnologias assistivas no ensino de pessoas com deficiência visual no curso técnico de Informática na Escola Prof. Raimundo Franco Teixeira/SENAI/ São Luís do Maranhão. Disponível em: <http:// bdigital.ufp.pt/bitstream/10284/3327/1/DM_23662.pdf>. Acesso: 10 set. 2012.

Rodriguez, C. L. (2011). A utilização de recursos audiovisuais em comunidades virtuais de aprendizagem: potencialidades e limites para comunicação e construção de conhecimentos em rede. Tese (Doutorado em Artes). Disponível em: $<$ http://www.bibliotecadigital.unicamp.br/document/?code $=000805896 \& \mathrm{fd}=\mathrm{y}>$. Acesso: 10 set. 2012.

Santos, P. K. (2012). Inclusão Digital de Professores: Uma proposta de construção de trajetórias personalizáveis em cursos na modalidade a distância. Dissertação (Mestrado em Educação). Disponível em: <http://tede.pucrs.br/tde_busca/arquivo .php?codArquivo=4114>. Acesso: 16. set. 2012.

Takahashi, T. (2000). Sociedade da informação no Brasil: livro verde. Brasília: Ministério da Ciência e Tecnologia. Disponível em: <http://www.mct.gov.br/index.php/content/view/18878.html>. Acesso: 02 jul. 2012.

Teixeira, A. C. (2010). Inclusão digital: Novas perspectivas para a informática educativa. 1 ed. Ijuí/RS: Edutora Unijuí. 